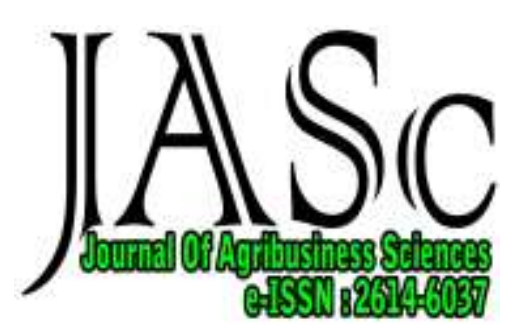

Oktober 2017 Volume 01 No. 01

\title{
FINANCIAL FEASIBILITY OF RICE RED RICE FARMING Oryza nivara (CASE STUDY: VILLAGE OF SARAN PADANG , DOLOK SILAU SUBDISTRICT, SIMALUNGUN REGENCY)
}

\section{KELAYAKAN FINANSIAL USAHATANI PADI BERAS MERAH (Oryza nivara) (STUDI KASUS : DESA SARAN PADANG, KECAMATAN DOLOK SILAU, KABUPATEN SIMALUNGUN)}

\author{
Ira Apriyanti, Gustina Siregar, Marlina Ariani Dalimunthe \\ Program Studi Agribisnis Fakultas Pertanian Universitas Muhammadiyah Sumatera Utara
}

\begin{abstract}
This research was conducted with the aim to know the financial feasibility of red rice farming. The population in this study is farmers of red rice in the village of Saran Padang, Dolok Silau District, Simalungun Regency. From the research results obtained the amount of rice production of red rice amounted to 1,014.40 Kg with the price of Rp. 5,700 / Kg, then the amount of farmer's acceptance is Rp. 5,782,080 seasonal crops. Total cost incurred of $R p$. 2.851 .535 planting season, so that the income of Rp. 2,930,545. Red rice farming is feasible to be cultivated based on NPV, IRR and BEP criteria with NPV value 11.251.995, IRR value is 76,76\%, and BEP value is overall profitable, with BEP value Rp. Rp. 2.811 BEP Production 287,87 Kg and BEP Revenue Rp. 1.640.213.
\end{abstract}

Keywords: Financial Feasibility, Rice Red, Farming

\section{ABSTRAK}

Penelitian ini dilakukan untuk mengetahui kelayakan finansial usahatani padi beras merah. Populasi pada penelitian ini adalah petani padi beras merah di Desa Saran Padang, Kecamatan Dolok Silau, Kabupaten Simalungun. Dari hasil penelitian diperoleh jumlah produksi padi beras merah sebesar $1.014,40 \mathrm{Kg}$ dengan harga Rp. 5.700/Kg, maka jumlah penerimaan petani sebesar Rp. 5.782 .080 permusim tanam. Total biaya yang dikeluarkan sebesar Rp. 2.851 .535 permusim tanam, sehingga diperoleh pendapatan sebesar Rp. 2.930.545. Usahatani padi beras merah layak untuk diusahakan berdasarkan kriteria NPV, IRR dan BEP dengan nilai NPV 11.251.995, nilai IRR 76,76 \%, dan nilai BEP secara keseluruhan menguntungkan, dengan nilai BEP Harga Rp. Rp. 2.811 BEP Produksi 287,87 Kg dan BEP Penerimaan Rp. 1.640.213.

Kata Kunci : Kelayakan Finansial, Padi Beras Merah, Usahatani

\section{A. PENDahuluan}

Indonesia merupakan negara agraris yang artinya sektor pertanian memiliki peran sangat penting. Peranan sektor pertanian ini mampu memberikan kontribusi yang besar dalam perekonomian bangsa, khususnya dalam memacu peningkatan pendapatan nasional. Sebagai salah satu pilar ekonomi negara, sektor pertanian diharapkan dapat meningkatkan pendapatan terutama dari penduduk pedesaan yang masih di bawah garis kemiskinan. ${ }^{1}$

Padi merupakan komoditas tanaman pangan yang penting di Indonesia. Penduduk Indonesia menjadikan beras sebagai bahan makanan pokok. Sebanyak $95 \%$ penduduk Indonesia mengonsumsi bahan makanan ini. ${ }^{2}$

Padi gogo atau padi ladang merupakan salah satu ragam budidaya padi, yaitu penanaman padi di lahan kering. Selain padi gogo, masih ada ragam budidaya padi yang lain yaitu padi sawah, padi rawa atau padi pasang surut, dan padi tadah hujan. Komposisi masing-masing ragam budidaya tersebut adalah padi sawah
$63 \%$, padi gogo $14 \%$, padi rawa $3 \%$ dan padi tadah hujan $20 \%$. $^{3}$

Kabupaten Simalungun merupakan Kabupaten penghasil Padi ladang terbesar di Sumatera Utara dengan jumlah produksi 188.995 ton dari tahun 2011 - 2015. Produksi yang tinggi dikarenakan daerahnya yang berbukit dan kesesuaian lahan untuk usahatani padi ladang. Produksi padi ladang lima tahun terakhir dapat dilihat pada tabel 1 . 
Tabel 1. Produksi Padi Ladang Menurut Kabupaten (ton) 2011 - 2015

\begin{tabular}{lccccc}
\hline \multirow{2}{*}{\multicolumn{1}{c}{ Kabupaten }} & \multicolumn{5}{c}{ Produksi } \\
\cline { 2 - 6 } & $\mathbf{2 0 1 1}$ & $\mathbf{2 0 1 2}$ & $\mathbf{2 0 1 3}$ & $\mathbf{2 0 1 4}$ & $\mathbf{2 0 1 5}$ \\
\cline { 2 - 6 } Nias & 61 & 1.557 & - & - & - \\
Mandailing Natal & 1.755 & - & 1.839 & 1.627 & 1.641 \\
Tapanuli Selatan & 8.862 & 1.557 & 7.189 & 9.527 & 8.704 \\
Tapanuli Tengah & 6.897 & 6.420 & 8.866 & 6.503 & 8.402 \\
Tapanuli Utara & 8.389 & 8.996 & 11.922 & 13.463 & 13.429 \\
Toba Samosir & 1.390 & 14.091 & 695 & 777 & 1.030 \\
Labuhanbatu & 229 & 805 & 337 & 299 & 413 \\
Asahan & 1.497 & 307 & 1.439 & 496 & 1.280 \\
Simalungun & $\mathbf{3 9 . 8 8 2}$ & $\mathbf{7 4 0}$ & $\mathbf{4 0 . 8 1 0}$ & $\mathbf{4 9 . 9 7 8}$ & $\mathbf{5 7 . 7 4 9}$ \\
Dairi & 20.282 & 40.200 & 14.870 & 8.871 & 24.224 \\
Karo & 29.861 & 19.418 & 34.384 & 20.852 & 22.866 \\
Deli Serdang & 2.947 & 31.946 & 1.339 & 1.372 & 1.546 \\
Langkat & 1.278 & 794 & 1.961 & 1.189 & 1.362 \\
Nias Selatan & 13.218 & 1.608 & 13.510 & 6.343 & 13.485 \\
Humbang Hasundutan & 5.231 & 7.369 & 4.461 & 4.995 & 5.346 \\
Pakpak Barat & 15.438 & 3.879 & 5.252 & 5.690 & 8.789 \\
Samosir & 6 & 11.099 & 6 & 3 & - \\
Serdang Bedagai & 591 & - & - & - & 22 \\
Batubara & - & 457 & - & - & - \\
Padang Lawas Utara & 944 & - & 1.480 & 1.911 & 716 \\
Padang Lawas & 2.723 & 890 & 2.907 & 2.334 & 970 \\
Labuhanbatu Selatan & 87 & 2.023 & 38 & 192 & 24 \\
Labuhan Batu Utara & 5.520 & 214 & 3.187 & 3.855 & 45 \\
Nias Utara & 53 & 10.245 & 48 & 246 & 50 \\
Nias Barat & - & 85 & - & - & - \\
& & & & & \\
\hline \multicolumn{1}{c}{ Sumber:BPS, 2014} & & & & &
\end{tabular}

\section{Sumber:BPS, $2014^{4}$}

Selain sebagai makanan pokok, beras juga menjadi sumber mata pencaharian bagi 25 juta rumah tangga petani, sehingga tidak mengherankan bila fluktuasi produksi dan distribusi beras turut mempengaruhi stabilitas nasional. $^{5}$

Beras merah merupakan salah satu kelompok padi-padian yang banyak memiliki manfaat bagi kesehatan manusia. Beras merupakan biji-bijian yang mengandung serat tinggi dengan karbohidrat sederhana. Karena itulah, beras merah sangat baik digunakan sebagai menu diet yang sehat. Kandungan serat yang tinggi akan membantu manusia agar selalu terjaga dalam keadaan kenyang. Manfaat dan khasiat Beras merah yang mengandung antioksidan sehingga terhindar dari serangan penyakit. Mengkomsumsi beras merah secara rutin setidaknya dua hari sekali untuk memperoleh manfaat tersebut bagi tubuh. Beras merah juga dapat menjaga keseimbangan pembentukan hormon serotinin. Beras merah mengandung vitamin B yang sangat baik untuk pembentukan hormon serotinin. Hormon serotinin merupakan hormon yang digunakan untuk menjalankan fungsi organ. ${ }^{6}$

Sumatera Utara merupakan salah satu sentra produksi beras nasional, namun luas lahan padi ladang tidak lebih besar dari luas lahan padi sawah. Simalungun merupakan daerah penghasil padi ladang terbesar di Sumatera Utara. Dan salah satu varietas padi ladang yang banyak ditanami oleh masyarakat sekitar adalah sigambiri merah yang merupakan varietas unggul asal Kabupaten Simalungun dan Karo. Varietas sigambiri merah juga sudah dikembangkan seluas $5000 \mathrm{Ha}$ di Simalungun. ${ }^{7}$

Berikut dapat dilihat data produksi padi ladang dari beberapa kecamatan yang memiliki produksi padi ladang di Kabupaten Simalungun yang berpotensi terdapat komoditas beras merah 


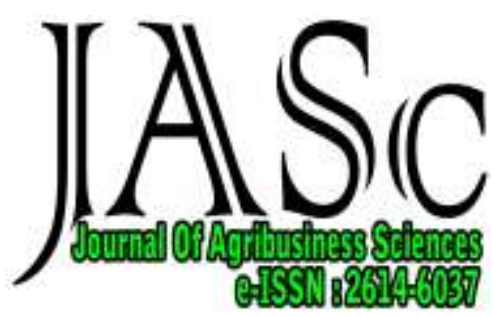

di dalamnya sebagaimana tertera pada tabel
Oktober 2017 Volume 01 No. 01 berikut : 
IRA APRIYANTI, GUSTINA SIREGAR, MARLINA ARIANI DALIMUNTHE

Tabel 2. Produksi Padi Ladang Menurut Kecamatan di Kabupaten Simalungun Tahun 2015

\begin{tabular}{lc}
\hline Kecamatan & Produksi \\
Silimakuta & Ton ) \\
Pamatang Silimahuta & 10.275 \\
Purba & 4.603 \\
Dolok Pardamean & 9.394 \\
Pamatang Sidamanik & 6.282 \\
Dolok Panribuan & 1.163 \\
Girsang Sipangan Bolon & 64 \\
Panei & 168 \\
Raya & 86 \\
Dolok Silau & 3.401 \\
Silau Kahean & $\mathbf{1 5 . 8 7 6}$ \\
Raya Kahean & 5.139 \\
\hline Kabupaten Simalungun & 1.298 \\
\hline \multicolumn{2}{c}{ Sumber:BPS SIMALUNGUN, $2015^{7}$} \\
\hline
\end{tabular}

Sumber:BPS SIMALUNGUN, $2015^{7}$

Dari tabel di atas dapat lihat bahwa Kecamatan Dolok Silau merupakan kecamatan dengan penghasil padi ladang terbesar di Kabupaten Simalungun. Masyarakat yang berada di Kecamatan Dolok Silau $\pm 80 \%$ menanam padi beras merah.

\section{B. METODE PENELITIAN}

Penelitian ini menggunakan metode studi kasus (case study) dengan pendekatan survei. Penentuan lokasi dilakukan secara purposive atau secara sengaja yaitu di Desa Saran Padang, Kecamatan Dolok Silau, Kabupaten Simalungun. Daerah ini ditentukan sebagai daerah penelitian berdasarkan pra survey yang dilakukan dengan tujuan-tujuan penelitian bahwa Desa Saran Padang merupakan daerah yang memiliki lahan budidaya padi beras merah terbesar di kecamatan Dolok Silau, kondisi ini dapat dilihat dari tabel 1 yang memperlihatkan besarnya jumlah produksi padi beras merah di Desa Saran Padang di bandingkan daerah lainnya.

Jumlah populasi yang terdapat di Desa Saran Padang sebanyak 247 petani. Jumlah sampel ditentukan berdasarkan teknik Slovin. Secara Matematis, Rumus Slovin yang kita gunakan untuk menentukan jumlah sampel adalah sebagai berikut :

$$
\begin{aligned}
\mathrm{n} & =\frac{N}{1+N \cdot(e)^{2}} \\
& =\frac{247}{1+247 \cdot 15 \%^{2}} \\
& =\frac{247}{1+247 \cdot(0,0225)} \\
\mathrm{n} & =\frac{247}{6,5575} \\
\mathrm{n} & =37,666=38 \text { sampel }
\end{aligned}
$$

Keterangan :

$\mathrm{n}=$ Jumlah Sampel

$\mathrm{N}=$ Jumlah Total Populasi

$\mathrm{e}=$ Batas Toleransi Error
Pada penelitian ini teknik penarikan sampel yang digunakan adalah teknik simple random sampling (pengambilan sampel acak sederhana), dengan menggunakan cara undian.

Jenis data yang dikumpulkan seperti data harga output, harga input yang digunakan dalam usahatani beras merah serta harga bahan baku dalam masing-masing usaha. Data sekunder diperoleh dari instansi terkait seperti Badan Pusat Statistik (BPS) Sumatera Utara, Dinas Pertanian Kecamatan Dolok Silau, Kantor Kecamatan Dolok Silau dan instansi terkait lainnya.

Metode analisis data yang digunakan adalah metode deskriptif kuantitatif dengan menghitung keseluruhan biaya tetap (FC) dan biaya variabel (VC) yang dikeluarkan oleh petani dan kemudian menggunakan metode tabulasi sederhana yaitu rumus analisa pendapatan yaitu :

Dimana :

$$
\mathrm{I}=\mathrm{TR}-\mathrm{TC}
$$

I : Pendapatan

TR : Total Penerimaan

TC : Total Cost ( biaya operasional keseluruhan)

Kelayakan finansial dianalisis dengan menggunakan digunakan metode deskriptif kuantitatif dengan menghitung kriteria investasi, diantaranya :

a. Net Present Value (NPV)

Menurut Kasmir dan Jakfar (2012), NPV merupakan selisih antara pengeluaran dan pemasukan yang telah di diskon dengan menggunakan social opportunity cost of capital sebagai diskon faktor, atau dengan kata lain merupakan arus kas yang diperkirakan pada masa yang akan datang yang didiskontokan pada saat ini. ${ }^{8}$ Secara singkat, formula untuk Net Present Value adalah sebagai berikut : 


\section{KELAYAKAN FINANSIAL USAHATANI PADI BERAS MERAH (Oryza nivara)}

Dimana :

$$
\mathrm{NPV}=\sum_{i=1}^{n} \frac{N B_{i}}{(1+i)^{n}}
$$

NB : Net Benefit $=$ Benefit - Cost

i : diskon faktor

$\mathrm{n}$ : umur ekonomis

Dengan kriteria :

NPV > 0 : usaha layak dilaksanakan

NPV $=0$ : usaha masih layak dilaksanakan

NPV < 0 : usaha tidak layak dilaksanakan

b. Internal Rate of Return (IRR)

Ukuran kedua dari kriteria investasi adalah

IRR. IRR merupakan tingkat suku bunga maksimum yang dapat dibayar oleh bisnis untuk sumberdaya yang digunakan karena bisnis membutuhkan dana lagi untuk biaya operasi dan investasi dan bisnis baru sampai pada tingkat pulang modal. Menurut Umar (2007 : 196). Metode ini digunakan untuk mencari tingkat bunga yang menyamakan nilai sekarang dari arus kas yang diharapkan di masa datang, atau penerimaan kas, dengan pengeluaran investasi awal. ${ }^{9}$ Rumus yang digunakan sebagai berikut

$$
\mathrm{IRR}=\mathrm{i}_{1}+\left(\frac{N P V_{1}}{N P V_{1}-N P V_{2}}\right) x\left(i_{2}-i_{1}\right)
$$

Keterangan :

$\mathrm{i}_{1}$ : discount rate yang menghasilkan NPV 1

$\mathrm{i}_{2}$ : discount rate yang menghasilkan NPV 2

$\mathrm{NPV}_{1}:$ Net Present Value 1

$\mathrm{NPV}_{2}$ : Net Presenet Value 2

Dengan kriteria usaha :

IRR $\geq \mathrm{i}$, berarti usaha ini bisa dilanjutkan

IRR $\leq \mathrm{i}$, berarti usaha ini lebih baik di tolak

c. Gross B/C Ratio

Gross B/C merupakan perbandingan antara present value benefit dengan present value cost. Rumus gross $\mathrm{B} / \mathrm{C}$ adalah sebagai berikut :

Gross $\mathrm{B} / \mathrm{C}=\frac{\sum_{t=1}^{n} \frac{B t}{(1+i) t}}{\sum_{t=1}^{n} \frac{C t}{(1+i) t}}$

Dimana :

Bt : Present Value Benefit

$\mathrm{Ct}$ : Present value Cost

Dengan kriteria :

Gross $\mathrm{B} / \mathrm{C} \geq 1$, berarti usaha layak untuk diusahakan

Gross $\mathrm{B} / \mathrm{C} \leq 1$, berarti usaha tidak layak untuk diusahakan. 1

\section{d. Break Event Point}

Break Event Point (BEP) adalah titik pulang pokok dimana total revenue $=$ total cost. Dilihat dari jangka waktu pelaksanaan sebuah proyek terjadinya titik pulang pokok atau TR = TC tergantung pada lama arus penerimaan usahatani padi beras merah sigambiri yang dapat menutupi segala biaya operasional dan pemeliharaan beserta biaya modal lainnya. ${ }^{11}$

Formula yang digunakan untuk menghitung BEP yang menunjukkan waktu pengambilan total cost, ada beberapa metode yang digunakan dalam menghitung BEP, diantaranya :

\section{BEP Harga $=\frac{T C}{Y}$}

Dimana :

TC : Total Cost (Biaya produksi keseluruhan)

Y : Produksi

Dengan kriteria jika harga > BEP Harga, maka usahatani padi beras merah menguntungkan.

2. BEP Produksi

BEP Produksi $=\frac{F C}{P-V C}$

Dimana :

FC : Biaya tetap

$\mathrm{P}$ : Price (Harga)

VC : Biaya Variabel Perunit

Dengan kriteria jika produksi > BEP produksi, maka usaha tersebut menguntungkan.

3. BEP Penerimaan

BEP Penerimaan $=\frac{F C}{1-\frac{V C}{S}}$

Dimana :

FC : Biaya Tetap

VC : Biaya Variabel

S : Supply atau penjualan

Dengan kriteria usaha tersebut akan layak jika penerimaan > BEP penerimaan maka usaha tersebut menguntungkan. ${ }^{12}$

\section{HASIL DAN PEMBAHASAN}

Biaya Investasi

Biaya investasi merupakan biaya awal yang dikeluarkan saat menjalankan usaha, dimana jumlahnya relatif besar. Biaya investasi ditanamkan atau dikeluarkan pada suatu usaha dengan tujuan memperoleh keuntungan dalam periode yang akan datang, yakni selama usaha tersebut dijalankan. Biaya yang termasuk didalam biaya investasi yaitu biaya tetap dan biaya variabel.

\section{Biaya Tetap}

Biaya tetap merupakan biaya yang besarnya tidak tergantung pada jumlah produksi yang dihasilkan. Biaya tetap yang dikeluarkan dalam usahatani padi beras merah meliputi biaya sewa lahan, biaya sewa traktor, biaya sewa alat perontok padi dan biaya penyusutan. Biaya tetap yang dikeluarkan oleh usahatani padi beras merah dapat dilihat pada tabel berikut: 
IRA APRIYANTI, GUSTINA SIREGAR, MARLINA ARIANI DALIMUNTHE

Tabel 2. Biaya Penyusutan

\begin{tabular}{|c|c|c|c|c|c|c|}
\hline No & $\begin{array}{c}\text { Komposisi } \\
\text { Biaya }\end{array}$ & Jumlah & $\begin{array}{c}\text { Harga } \\
\text { Satuan (Rp) }\end{array}$ & Total (Rp) & $\begin{array}{c}\text { Penyusutan } \\
\text { Permusim }\end{array}$ & $\begin{array}{c}\text { Penyusutan } \\
\text { Pertahun (Rp) }\end{array}$ \\
\hline \multicolumn{7}{|c|}{ A. Peralatan Produksi } \\
\hline 1 & Cangkul & 3 Unit & & 210.000 & 18.225 & 36.451 \\
\hline 2 & Arit & 3 Unit & 10.000 & 75.000 & 6.955 & 13.911 \\
\hline 3 & Garuk & 1 Unit & 25.000 & 5.488 & 2.744 & 5.488 \\
\hline \multirow[t]{2}{*}{4} & $\begin{array}{l}\text { Alat } \\
\text { Semprot }\end{array}$ & 1 Unit & $\begin{array}{c}25.000 \\
800.000\end{array}$ & 800.000 & 64.666 & 129.333 \\
\hline & & & Jumlah & & 92.590 & 185.180 \\
\hline
\end{tabular}

Sumber : Data Primer Diolah, 2017

Pada tabel di atas menunjukkan bahwa biaya yang dikeluarkan oleh petani adalah sebesar Rp. 92.590 permusim dan Rp. 185.180 Tabel 3. Biaya Tetap Usahatani Padi Beras Merah

\begin{tabular}{clcccc}
\hline No & \multicolumn{1}{c}{ Komposisi Biaya } & Jumlah (Ha) & $\begin{array}{c}\text { Harga/ } \\
\text { Rante (Rp) }\end{array}$ & $\begin{array}{c}\text { Biaya } \\
\text { Permusim } \\
\text { Tanam }\end{array}$ & $\begin{array}{c}\text { Biaya } \\
\text { Pertahun }\end{array}$ \\
\hline 1 & Sewa Lahan & 1.112 .100 & 125.400 & 556.050 & 1.112 .100 \\
2 & Sewa Traktor & 625.262 & 1.000 .000 & 312.631 & 625.262 \\
3 & Sewa Alat Perontok Padi & 400.000 & - & 200.000 & 400.000 \\
4 & Total Penyusutan & 185.180 & - & 92.590 & 185.180 \\
\hline \multicolumn{7}{c}{ Total Biaya Tetap } \\
\hline
\end{tabular}

Sumber : Data Primer Diolah, 2017

Dapat dilihat dari tabel di atas bahwa biaya tetap adalah biaya sewa lahan yang dikeluarkan dalam satu musim tanam sebesar Rp. 556.050 dan untuk satu tahun biaya yang dikeluarkan sebesar Rp. 1.112.100. Biaya sewa traktor untuk satu kali musim tanam sebesar Rp. 312.631, biaya sewa alat perontok padi (Komben) sebesar Rp. 200.000. untuk satu kali musim panen dan total biaya penyusutan untuk satu kali musim tanam sebesar Rp. 92.590. Maka didapatlah total biaya tetap yang dikeluarkan sebesar $\mathrm{Rp}$. pertahun. Dalam usahatani ini terdapat dua kali musim tanam dalam satu tahun.

Tabel 4. Biaya Variabel Usahatani Padi Beras Merah

\begin{tabular}{|c|c|c|c|c|c|c|}
\hline No & Komposisi Biaya & Jumlah & Satuan & $\begin{array}{l}\text { Harga / } \\
\text { Satuan }\end{array}$ & $\begin{array}{c}\text { Biaya } \\
\text { Permusim } \\
\text { Tanam (Rp) }\end{array}$ & $\begin{array}{c}\text { Biaya } \\
\text { Pertahun (Rp) }\end{array}$ \\
\hline 1 & Bibit & 19,89 & $\mathrm{Kg}$ & 5700 & 113.400 & 226.800 \\
\hline 2 & Pupuk & 8,2 & $\mathrm{Kg}$ & - & 55.049 & 110.098 \\
\hline 3 & Pestisida & 85,9 & $\mathrm{ml}$ & - & 49.873 & 99.746 \\
\hline 4 & Goni & 15 & Buah & 2.500 & 200.000 & 400.000 \\
\hline 5 & Tenaga Kerja Luar Keluarga & 10 & HK & 70.000 & 787.629 & 1.575 .258 \\
\hline \multirow[t]{2}{*}{6} & $\begin{array}{lll}\text { Tenaga } & \text { Kerja } & \text { Dalam } \\
\text { Keluarga } & & \\
\end{array}$ & 7 & HK & 70.000 & 484.313 & 968.626 \\
\hline & Total Biaya Variabel & & & & 1.690 .264 & 3.380 .528 \\
\hline
\end{tabular}

Pada tabel di atas biaya yang dikeluarkan untuk pengadaan bibit untuk permusim tanam sebesar Rp. 113.400, biaya untuk pengadaan pupuk permusim tanam sebesar Rp. 55.049, biaya untuk pengadaan pestisida permusim tanam sebesar Rp. 49.873, biaya untuk pengadaan goni sebesar Rp. 200.000 untuk permusim tanam, biaya tenaga kerja luar keluarga sebesar Rp. 787.629, biaya untuk tenaga kerja dalam
1.161.271 untuk satu kali musim tanam dan biaya untuk satu tahun sebesar Rp. 2.322.542.

Biaya Variabel

Biaya variabel merupakan biaya yang harus dikeluarkan seiring dengan bertambah atau berkurangnya produksi. Biaya variabel akan mengalami perubahan jika volume produksi berubah. Besarnya biaya variabel yang dikeluarkan setiap sekali musim tanam untuk usahatani padi beras merah yaitu Rp. 1.690.264. Biaya-biaya variabel tersebut dapat dilihat dari tabel berikut : 


\section{KELAYAKAN FINANSIAL USAHATANI PADI BERAS MERAH (Oryza nivara)}

mengetahui total biaya yang dikeluarkan oleh Petani padi beras merah selama periode produksi dalam satu musim tanam.

Besarnya biaya total yang dikeluarkan oleh Petani pada usahatani padi beras merah selama Tabel 5. Biaya Total Usahatani Padi Beras Merah

\begin{tabular}{|c|c|c|c|}
\hline No & Uraian & Total Biaya Produksi Permusim & $\begin{array}{c}\text { Total Biaya } \\
\text { Pertahun }\end{array}$ \\
\hline 1 & Total Biaya Tetap & 1.161 .271 & 2.322 .542 \\
\hline 2 & Total Biaya Variabel & 1.690 .264 & 3.380 .528 \\
\hline & Jumlah & 2.851 .535 & 5.703 .070 \\
\hline
\end{tabular}

Penerimaan Usahatani

Penerimaan adalah nilai yang diperoleh dari seluruh hasil produksi pertanian dengan harga jual produksi. Harga jual padi beras merah sebesar Rp. $5.700 / \mathrm{Kg}$ dengan total penerimaan permusim tanam sebesar Rp. satu musim tanam adalah sebesar Rp. 2.851.535 Untuk lebih jelasnya mengenai biaya total pada usahatani padi beras merah dapat dilihat pada tabel berikut :

Tabel 6. Penerimaan Usahatani

\begin{tabular}{ccccc}
\hline $\begin{array}{c}\text { Produksi } \\
\begin{array}{c}\text { Permusim Tanam } \\
(\mathrm{Kg})\end{array}\end{array}$ & $\begin{array}{c}\text { Luas Lahan } \\
(\mathrm{Ha})\end{array}$ & Harga/Kg & $\begin{array}{c}\text { Penerimaan } \\
\text { Permusim (Rp) }\end{array}$ & $\begin{array}{c}\text { Penerimaan } \\
\text { Pertahun (Rp) }\end{array}$ \\
\hline $1.014,40$ & 0,34 & 5.700 & 5.782 .080 & 11.564 .160 \\
\hline \multicolumn{2}{l}{ Sumber : Data Primer Diolah, 2017} & &
\end{tabular}

Pendapatan Petani Padi Beras Merah

Pendapatan adalah nilai uang yang diperoleh petani dengan menghitung selisih antara total penerimaan dengan total biaya produksi yang dikeluarkan selama proses produksi. Pendapatan petani padi beras merah di
5.782.080 dan penerimaan yang diperoleh petani sebesar Rp. 11.564.160 untuk dua kali musim tanam. Jumlah penerimaan usahatani padi beras merah dapat dilihat pada tabel berikut:

Tabel 7. Pendapatan Usahatani

\begin{tabular}{lcccc}
\hline \multicolumn{1}{c}{ Uraian } & $\begin{array}{c}\text { Luas Lahan } \\
(\text { Ha })\end{array}$ & $\begin{array}{c}\text { Pendapatan } \\
\text { Permusim Tanam }\end{array}$ & $\begin{array}{c}\text { Pendapatan } \\
\text { Pertahun }\end{array}$ & $\begin{array}{c}\text { Pendapatan } \\
\text { Permusim (1 Ha) }\end{array}$ \\
\hline Biaya Tetap & 0,34 & 1.161 .271 & 2.322 .542 & 3.414 .136 \\
Biaya Variabel & 0,34 & 1.690 .264 & 3.380 .528 & 4.969 .376 \\
Penerimaan & $\mathbf{0 , 3 4}$ & $\mathbf{5 . 7 8 2 . 0 8 0}$ & $\mathbf{5 . 8 6 1 . 0 9 0}$ & $\mathbf{1 6 . 9 9 9 . 3 1 5}$ \\
Pendapatan & $\mathbf{0 , 3 4}$ & $\mathbf{2 . 9 3 0 . 5 4 5}$ & $\mathbf{4 . 5 6 4 . 5 2 4}$ & $\mathbf{8 . 6 1 5 . 8 0 2}$ \\
\hline
\end{tabular}

Sumber : Data Primer Diolah, 2017

Dari tabel di atas dapat dilihat jumlah pendapatan untuk luas lahan 0,34 Ha sebesar Rp. 2.930.545 dan apabila pendapatan tersebut di konversikan ke dalam luasan $1 \mathrm{Ha}$ maka didapatlah pendapatan sebesar Rp. 8.615.802.
Desa Saran Padang Kecamatan Dolok Silau Kabupaten Simalungun adalah sebesar Rp. 2.930.545 untuk satu kali musim tanam dan pendapatan petani pertahunnya sebesar Rp. 5.861.090.
Asumsi Analisis Keuangan

Analisis keuangan yang dilakukan berdasarkan asumsi yang telah dibuat. Asumsi dalam analisis keuangan dapat dilihat pada tabel berikut ini : 
IRA APRIYANTI, GUSTINA SIREGAR, MARLINA ARIANI DALIMUNTHE

Tabel 8. Asumsi Dalam Analisis Keuangan

\begin{tabular}{clcc}
\hline No & \multicolumn{1}{c}{ Asumsi } & Satuan & Nilai \\
\hline 1 & Periode Produksi & Bulan & 12 \\
2 & Periode Proyeksi & Tahun & 1 \\
3 & Musim Tanam & Kali/Tahun & 2 \\
4 & Lama Permusim Tanam & Bulan & 6 \\
5 & Kondisi Tanaman & Ha & 0,34 \\
& a. Luas Lahan & Kg & $1.014,40$ \\
& b. Produksi Padi Beras Merah & Rp/Kg & 5.700 \\
6 & $\quad$ Harga Penjualan & Persen & $13 \%$ \\
7 & a. Harga Jual Padi Beras Merah & &
\end{tabular}

Sumber : Data Primer Diolah, 2017

Analisis Kelayakan Finansial Usahatani Padi Beras Merah

Analisis kelayakan ini berkaitan dengan keputusan investasi agar mendapatkan keuntungan yang maksimal dan menghindari adanya pemborosan sumberdaya. Analisis kelayakan finansial dihitung berdasarkan nilai manfaat bersih (net benefit) dengan discount factor $13 \%$. Nilai net benefit yang diperoleh tersebut dijadikan dasar perhitungan kelayakan finansial berdasarkan kriteria investasi yaitu : Net Present Value (NPV), Internal Rate of Return (IRR), Gross Benefit Cost (Gross B/C) dan Break Event Point (BEP).

Net Present Value (NPV)

Dalam mengkaji NPV digunakan tingkat suku bunga bank sebesar $13 \%$, hal ini sesuai dengan kebijakan statistik perbankan (2016). Perhitungan NPV dapat dilihat pada rumus dibawah ini :

$\mathrm{PV}=$ Net Benefit $\mathrm{x}$ Df

$\mathrm{NPV}=\sum \mathrm{PV}$

$=11.251 .995$

Maka didapat perhitungan nilai NPV adalah sebesar Rp. 11.251.995 karena 11.251.995 > 0 maka dapat dikatakan usahatani padi beras merah layak secara finansial untuk dilaksanakan. Dengan arti bahwa investasi awal yang dilakukan yaitu sebesar Rp. 14.250.675 maka untuk 5 musim tanam atau 2,5 tahun ke depan usaha ini masih mendapat keuntungan sebesar Rp. 11.251.995

Internal Rate of Return (IRR)

Internal rate of return merupakan tingkat pengembalian usaha terhadap modal yang ditanamkan. Perhitungan IRR dapat dilihat pada rumus dibawah ini :

$$
\begin{aligned}
\text { IRR } & =\mathrm{i} 1+\frac{N P V 1}{N P V 1-N P V 2} \times(\mathrm{i} 2-\mathrm{i} 1) \\
& =0,13+\frac{11.251 .995}{11.251 .995-10.899 .155} \times(0,15-0,13) \\
& =0,13+\frac{11.251 .995}{352.840} \times(0,02) \\
& =0,13+31,88 \times 0,02 \\
& =0,13+0,6376 \\
& =0,7676 \\
& =76,76 \%
\end{aligned}
$$

Hasil perhitungan nilai IRR adalah sebesar $76,76 \%$. Dimana 76,76 \% lebih besar dari pada tingkat suku bunga bank yang digunakan yaitu $13 \%$. Artinya untuk suka bunga yang berlaku di bandingkan dengan nilai IRR yang diperoleh, maka 76,76 \% petani dapat mengembalikan pinjaman yang dilakukan. sehingga dapat disimpulkan bahwa usahatani ini layak secara finansial untuk dilaksanakan.

Gross Benefit Cost Ratio (Net B/C)

Gross B/C merupakan perbandingan antara benefit kotor yang telah di discount factor dengan cost secara keseluruhan yang telah di discount :

$$
\begin{aligned}
\text { Gross B/C }= & \frac{11.251 .995}{12.045 .740} \\
& =0,934
\end{aligned}
$$

Dari hasil perhitungan diatas nilai $\mathrm{B} / \mathrm{C}$ adalah 0,934 . Dimana $0,934<1$, yang artinya jika petani mengeluarkan biaya sebesar Rp. 1, maka petani memperoleh keuntungan sebesar 0,934. Berdasarkan hasil perhitungan dapat disimpulkan bahwa usahatani padi beras merah tidak layak untuk dilaksanakan. Hal ini diakibatkan besarnya biaya dalam usahatani dibandingkan dengan pendapatan. Besarnya biaya usahatani dikarenakan tingginya upah tenaga kerja di daerah penelitian serta sulitnya mencari tenaga kerja yang diakibatkan masyarakat di daerah penelitian rata-rata memiliki lahan pertanian.

\section{Break Event Point (BEP)}

Break Event Point adalah keadaan suatu usaha ketika dikatakan tidak memperoleh laba atau tidak mengalami kerugian atau disebut juga sebagai titik impas. BEP dapat terjadi apabila total penghasilan sama dengan total biaya yang dikeluarkan selama usaha berjalan. Perhitungan BEP dalam hal ini ada 3 yaitu BEP Harga, BEP Produksi dan BEP Penerimaan, untuk lebih jelasnya dapat dilihat pada perhitungan berikut ini :

$$
\begin{aligned}
& \text { 1. BEP Harga }=\frac{T C}{Y} \\
& =\frac{2.851 .535}{1.014,40}
\end{aligned}
$$




\section{KELAYAKAN FINANSIAL USAHATANI PADI BERAS MERAH (Oryza nivara)}

$$
=\text { Rp. } 2.811
$$

Hasil perhitungan di atas menunjukkan bahwa nilai BEP Harga sebesar Rp. 2.811. Dimana harga padi beras merah yaitu Rp. 5.700 $>$ Rp. 2.811. maka dapat disimpulkan bahwa usahatani padi beras merah memperoleh keuntungan. Artinya dalam usahatani padi beras merah akan memberikan keuntungan apabila harga jual padi beras merah diatas Rp. 2.811.

2. BEP Produksi $=\frac{F C}{P-A V C}$

$$
\begin{aligned}
& =\frac{1.161 .271}{5.700-1.666} \\
& =287,87 \mathrm{Kg}
\end{aligned}
$$

Berdasarkan hasil perhitungan di atas didapatkan nilai BEP Produksi sebesar 287,87 $\mathrm{Kg}$. Dimana total produksi padi beras merah sebesar $1.014,40 \mathrm{Kg}>287,87 \mathrm{Kg}$, maka dapat disimpulkan bahwa usahatani padi beras merah menguntungkan. Usahatani padi beras merah akan mendapatkan keuntungan apabila produksi padi beras merah diatas $287,87 \mathrm{Kg}$.

Produksi padi beras merah dengan luas lahan 0,34 $\mathrm{Ha}$ sebesar $1.014,40 \mathrm{Kg}$, jika produksi tersebut di konversi ke luas lahan 1 Ha, maka jumlah produksi padi beras merah menjadi 2.982,336 Kg. Berdasarkan hasil penelitian yang dilakukan Badan Litbang Pertanian bahwa produksi padi rata-rata nasional sebesar 5,14 ton/Ha sementara rata-rata produksi padi beras merah sebesar 2,982 ton/Ha. Padi beras putih memiliki rata-rata produksi yang lebih besar dibandingkan dengan rata-rata produksi padi beras merah.

3. BEP Penerimaan $=\frac{F C}{1-\frac{V C}{S}}$

$$
\begin{aligned}
& =\frac{1.161 .271}{1-\frac{1.690 .264}{5.782 .080}} \\
& =\text { Rp. } 1.640 .213
\end{aligned}
$$

Berdasarkan hasil perhitungan di atas didapatkan nilai BEP Penerimaan sebesar Rp. 1.640.213 dengan total penerimaan petani padi beras merah sebesar Rp. 5.782.080. dimana Rp. $5.782 .080>$ Rp. 1.640.213, maka dapat disimpulkan bahwa usahatani padi beras merah menguntungkan untuk diusahakan dengan penerimaan harus di atas Rp. 1.640.213.

\section{KESIMPULAN DAN SARAN}

Kesimpulan

Dari hasil penelitian yang dilakukan maka didapatlah kesimpulan sebagai berikut :

1. Penerimaan dari usahatani padi beras merah yang diperoleh sebesar Rp. 5.782.080 dalam satu kali penanaman.

2. Pendapatan yang diperoleh dari usahatani padi beras merah sebesar Rp. 2.930.545 dalam satu kali panen.

3. Analisis kelayakan aspek finansial pada usahatani padi beras merah menunjukkan bahwa nilai NPV, IRR, dan BEP yang diperoleh memenuhi ukuran kelayakan.
Dan berdasarkan kriteria gross B/C usahatani padi beras merah tidak layak. Saran

1. Para petani padi beras merah harus memperhatikan biaya-biaya yang dikeluarkan agar tidak menurunkan pendapatan petani.

2. Petani diharapkan mencari informasi dan teknologi yang tepat untuk usahatani padi beras merah guna menghasilkan produksi yang lebih tinggi

3. Kepada pemerintah untuk lebih memperhatikan petani padi beras merah di Desa Saran Padang agar petani mendapatkan bantuan baik pengetahuan maupun pinjaman dana untuk mampu meningkatkan produksi padi beras merah.

\section{DAFTAR PUSTAKA}

1. Kuncoro, 2010. Masalah, Kebijakan dan Politik Ekonomi Pembangunan. Erlangga. Jakarta

2. Swastika, D.K.S, J. Wargiono, B. Sayaka, A. Agustian, dan V. Darwis. 2007. Kinerja dan masa depan pembangunan pertanian tanaman pangan. hlm. 1-22. Dalam K. Suradisastra, Y. Yusdja, dan P.U. Hadi (Ed.). Prosiding Kinerja dan Prospek Pembangunan Pertanian.Pusat Analisis Sosial Ekonomi dan Kebijakan Pertanian, Bogor.

3. Prasetyo, Y. T. 2006. Bertanam Padi Gogo Tanpa Olah Tanah. Penebar Swadaya. Jakarta

4. Badan Pusat Statistik Sumatera Utara, 2014

5. Balai Besar Penelitian Tanaman Padi, 2009. Refleksi Kinerja BB Padi Tahun 2005

2009.http://bbpadi.litbang.pertanian.go.id/i ndex.php/varietas/24-profil/ refleksi-5tahun.

6. Susi Naluri, 2010. Analisis Komparatif Usahatani Beras Merah Organik (Oryza nivara) dan Beras Putih Organik (Oryza sativa). Jurnal Agribisnis Pertanian. Universitas Sebelas Maret.

7. BPS Kabupaten Simalungun Tahun 2015

8. Kasmir dan Jakfar. 2012. Studi Kelayakan Bisnis. Kencana Prenada Group. Jakarta

9. Umar, Husein, 2007. Studi Kelayakan Bisnis. Edisi ketiga revisi. PT Gramedia Pustaka Utama. Jakarta.

10. Ibrahim Yacob, H.M., 2009. Studi Kelayakan Bisnis. Rineka Cipta. Jakarta

11. Kasmir dan Jakfar. 2007. Studi Kelayakan Bisnis. Kencana. Jakarta

12. Suratiyah, K. 2006. Ilmu Usahatani. Penebar Swadaya. Jakarta. 
IRA APRIYANTI, GUSTINA SIREGAR, MARLINA ARIANI DALIMUNTHE 